\title{
Growth and Maturation of Haddock (Melanogrammus aeglefinus) in Icelandic Waters
}

\author{
Lorna Taylor and Gunnar Stefánsson \\ Marine Research Institute, P. O. Box 1390, Skúlagata 4 \\ Reykjavík, Iceland
}

\begin{abstract}
Growth and maturation of haddock (Melanogrammus aeglefinus), in Icelandic waters have shown considerable spatial and temporal variation in the past several decades. After 1988 haddock have matured much earlier than in earlier decades and haddock in some areas appear to mature young and also show stunted growth. The paper compares possible reasons for this phenomenon and evaluates different models of the growth-maturation process through the use of otolith radii and length-at-age as well as biological samples from groundfish surveys and commercial catches. It is found that there is considerable spatial and temporal variation in growth and maturity. Some of the variability may be due to some form of competition among year-classes whereas there are also indications of a link between growth and maturation in certain areas.
\end{abstract}

Key words: age determination, growth, haddock, Iceland area, maturity

\section{Introduction}

Considerable changes have been observed in growth and maturation of haddock (Melanogrammus aeglefinus) in Icelandic waters in the period from 1970 to 1998 (Anon., MS 1998). In particular, observations in the commercial catches of an increase in the proportion of young mature fish (Table 1, from Anon., MS 1998) along with substantial variation in observed mean weight-at-age (Table 2, from Anon., MS 1998) are of considerable interest. If the variation in growth is density linked, this could potentially be of importance for the utilisation of the stock (Beverton and Holt, 1957) and might have an effect on predictions of medium-term yield (Helser and Brodziak, 1998).

Given that the proportion mature-at-age is an important determinant of spawning stock biomass, there is considerable interest in determining whether the changes in maturity-at-age are real, factors affecting the spawning potential or artifacts caused by sampling, as has been seen for some species (e.g. cod (Gadus morhua) as in Stefánsson, MS 1992).

In other areas considerable research has been undertaken to elucidate which factors are important in the growth-maturation process for haddock.
Research on haddock in captivity, described by Hislop et al. (1978), mainly focuses on fecundity, indicating that fecundity is higher with increased food supply. The evidence for food supply increasing the proportion of fish spawning is, however, too scant for firm conclusions. In the North Sea it is well known that haddock recruitment is highly variable (Hislop, 1988), with size and age composition varying between years. Furthermore, Hislop (1988) found that fish maturing young (age 2) produce smaller and lighter eggs than older fish.

Work on haddock in the Barents Sea, (Sonina, 1981; Kovtsova, MS 1987) indicates that there is considerable variability in length and weight-at-age from one year-class to another. Variation in growth rate appears to be dependent on food supply. Population density and environmental factors such as temperature may also be important. There are indications that growth rate rather than length is the important factor in maturation (Sonina, 1981). The faster growing fish appear to mature younger and smaller than slow growing fish, which mature older, and at a greater length.

It is quite plausible that growth of haddock may be density dependent, particularly since the yearclass size tends to vary by several orders of magnitude for this species. This effect seems to be present 
TABLE 1. Proportion mature by age and year as used in Iceland haddock stock assessments, from Anon., MS 1998.

\begin{tabular}{lcccccccc}
\hline \hline & \multicolumn{7}{c}{ Age (years) } \\
Year & 2 & 3 & 4 & 5 & 6 & 7 & 8 & 9 \\
\hline 1978 & 0.00 & 0.13 & 0.30 & 0.46 & 0.68 & 0.86 & 0.96 & 1.00 \\
1979 & 0.00 & 0.13 & 0.30 & 0.46 & 0.68 & 0.86 & 0.96 & 1.00 \\
1980 & 0.00 & 0.13 & 0.30 & 0.46 & 0.68 & 0.86 & 0.96 & 1.00 \\
1981 & 0.00 & 0.13 & 0.30 & 0.46 & 0.68 & 0.86 & 0.96 & 1.00 \\
1982 & 0.00 & 0.13 & 0.30 & 0.46 & 0.68 & 0.86 & 0.96 & 1.00 \\
1983 & 0.00 & 0.13 & 0.30 & 0.46 & 0.68 & 0.86 & 0.96 & 1.00 \\
1984 & 0.00 & 0.13 & 0.30 & 0.46 & 0.68 & 0.86 & 0.96 & 1.00 \\
1985 & 0.01 & 0.10 & 0.40 & 0.43 & 0.72 & 0.67 & 0.92 & 0.89 \\
1986 & 0.02 & 0.19 & 0.43 & 0.66 & 0.83 & 0.87 & 0.95 & 0.99 \\
1987 & 0.02 & 0.11 & 0.41 & 0.52 & 0.79 & 0.78 & 1.00 & 0.96 \\
1988 & 0.01 & 0.22 & 0.38 & 0.77 & 0.79 & 0.93 & 0.90 & 1.00 \\
1989 & 0.04 & 0.20 & 0.53 & 0.72 & 0.80 & 1.00 & 1.00 & 1.00 \\
1990 & 0.11 & 0.28 & 0.59 & 0.81 & 0.84 & 0.92 & 0.90 & 1.00 \\
1991 & 0.04 & 0.20 & 0.58 & 0.75 & 0.82 & 0.91 & 0.94 & 1.00 \\
1992 & 0.04 & 0.14 & 0.42 & 0.77 & 0.86 & 0.87 & 0.71 & 1.00 \\
1993 & 0.12 & 0.33 & 0.47 & 0.66 & 0.88 & 0.97 & 0.93 & 0.85 \\
1994 & 0.25 & 0.32 & 0.57 & 0.78 & 0.86 & 1.00 & 0.90 & 1.00 \\
1995 & 0.16 & 0.49 & 0.43 & 0.78 & 0.83 & 0.69 & 1.00 & 1.00 \\
1996 & 0.17 & 0.36 & 0.58 & 0.65 & 0.78 & 0.73 & 0.96 & 0.98 \\
1997 & 0.09 & 0.44 & 0.66 & 0.71 & 0.75 & 0.86 & 0.89 & 1.00 \\
1998 & 0.03 & 0.48 & 0.68 & 0.78 & 0.76 & 0.85 & 0.91 & 1.00 \\
\hline
\end{tabular}

TABLE 2. Mean weight-at-age as used in Iceland haddock stock assessments, from Anon., MS 1998.

\begin{tabular}{lcccccccc}
\hline \hline & \multicolumn{7}{c}{ Age (years) } \\
\cline { 2 - 10 } Year & 2 & 3 & 4 & 5 & 6 & 7 & 8 & 9 \\
\hline 1978 & 620 & 960 & 1410 & 2030 & 2910 & 3800 & 4560 & 4720 \\
1979 & 620 & 960 & 1410 & 2030 & 2910 & 3800 & 4560 & 4720 \\
1980 & 837 & 831 & 1306 & 2207 & 2738 & 3188 & 3843 & 4506 \\
1981 & 584 & 693 & 1081 & 1656 & 2283 & 3214 & 3409 & 4046 \\
1982 & 330 & 819 & 1365 & 1649 & 2329 & 3012 & 3384 & 3965 \\
1983 & 655 & 958 & 1436 & 1827 & 2355 & 2834 & 3569 & 4308 \\
1984 & 980 & 1041 & 1476 & 2105 & 2460 & 3028 & 3014 & 3807 \\
1985 & 599 & 1002 & 1783 & 2201 & 2727 & 3431 & 3783 & 4070 \\
1986 & 867 & 187 & 1755 & 2377 & 2710 & 3591 & 3760 & 4135 \\
1987 & 446 & 1048 & 1629 & 2373 & 2984 & 3550 & 4483 & 4667 \\
1988 & 468 & 808 & 1474 & 2230 & 2934 & 3545 & 3769 & 4574 \\
1989 & 745 & 856 & 1170 & 2010 & 2879 & 4109 & 4035 & 4706 \\
1990 & 357 & 716 & 1039 & 1542 & 2403 & 3458 & 4186 & 4969 \\
1991 & 409 & 868 & 1111 & 1546 & 2035 & 2849 & 3464 & 4642 \\
1992 & 320 & 856 & 1253 & 1597 & 2088 & 2529 & 3133 & 4022 \\
1993 & 420 & 756 & 1372 & 1870 & 2360 & 2888 & 2975 & 3442 \\
1994 & 568 & 720 & 1058 & 1742 & 2380 & 2785 & 3447 & 3156 \\
1995 & 457 & 874 & 1145 & 1366 & 2079 & 2853 & 3251 & 3899 \\
1996 & 387 & 841 & 1189 & 1528 & 1816 & 2641 & 3499 & 3526 \\
1997 & 450 & 829 & 1192 & 1663 & 1934 & 2360 & 3059 & 3010 \\
\hline
\end{tabular}

in the Barents Sea (Sonina, 1981) where growth appears to depend on the total population numbers, rather than only that of the year-class. Similarly, in the North Sea in the 1960s, large year-classes ini- tially showed low growth (as did the subsequent year-class) but after the youngest ages growth increased and became comparable with that of much smaller year-classes (Jones, 1983; Cushing, 1984; 
Hislop, 1996). This may indicate that competition effects from an abundant year-class only affect smaller and younger fish. In particular it was found that the year-classes from the years before the large year-classes grew rapidly despite spending all but the first year in a period of high haddock abundance, (Hislop, 1996). The largest year-classes in the North Sea have been followed by two very small yearclasses, suggesting that large year-classes may lower recruitment in the following years, (Cook and Armstrong, 1986). In the Barents Sea, during the period from 1962-86, the highest growth was observed in the 1982 year-class, despite 1982 being a strong year-class, as the population biomass was low (Kovtsova, MS 1987).

Naturally various environmental factors may be of importance in determining the growth of haddock as that of any fish species. In particular, Cushing (1984) related the timing of the Calanus spring bloom with gadoid recruitment as a later spring outburst of Calanus provides gadoids with a greater food supply. Cushing (1984) did not find conclusive evidence of a relationship between haddock and Calanus after 1962, although a relationship was evident in data from 1933 to 1961, but suggested that cod through predation and competition may affect haddock.

Although density dependence is a plausible mechanism, it is by no means universal, as it has been found that mean lengths-at-age of haddock in the North Sea in the 1960s were comparable with those of the 1950s (higher than 1920s) despite the stock biomass being considerably higher (Jones, 1983). Indications for density dependent growth have been reported for haddock on Georges Bank (Ross and Nelson, 1992), but investigations of density dependent growth are hampered by the fact that several mechanisms can sometimes result in the same measurements. Notably, enhanced survival of small fish in good year-classes may give the appearance of density dependent growth within a yearclass (Bromley, 1989).

If fish grow more slowly after maturation, as energy is required for reproduction, a faster growing population will mature younger and smaller and subsequently may be smaller at age. Haddock in warmer water grow faster, which may be a reason why the North Sea haddock population (Hislop et $a l ., 1978)$ matures younger and at a shorter length than Icelandic haddock which in turn matures younger and shorter than Barents Sea haddock.
It is thus possible that a considerable portion of the variation could be due to environmental factors, such as warmer water producing a larger year class which are able to mature faster (and therefore at a shorter length). In the Arcto-Boreal waters warmer water also tends to imply more food and faster growth.

The questions raised above for haddock are to some extent of a general ecological nature and it is of some interest to note which factors play a role for other species, in order to shed some light on which effects might be expected for haddock in Icelandic waters. Considerable research has been conducted on North Sea plaice (Pleuronectes platessa) in order to understand and link the growth and maturation processes (Rijnsdorp, 1993). For this species, length and age at maturity have changed this century with fish maturing younger and smaller. It is not clear whether this is a genotypic or phenotypic change, but several aspects are of interest. For example, if the maturation process takes more than 1 year, then early growth appears to be more influential than growth in the year immediately prior to maturation. The entire growth history is therefore important for plaice with immature female plaice smaller than mature plaice, both in the year of sampling and earlier.

In addition to flatfish, the growth and maturation of salmonids has been extensively studied, both in captivity and in the wild. For male Atlantic salmon (Salmo salar) parr, it appears that there is a minimum length for maturation and early maturity follows faster average growth (Myers et al., 1986). Another aspect in this case is that after gonadal development, mature fish appear to grow slower than immature fish of the same age (Myers et al., 1986). Previous changes in growth thus appear to explain changes in the proportion mature from year to year.

Naturally, these growth and maturity variations are due to some physiological variations which stem in one way or another from the past and present environment in accordance with the response dictated genetically. It has been found that higher fat levels and/or early (within a year) replenishment of fat stores leads to early maturation in salmon (Rowe et al., 1991). It is therefore quite plausible that the onset of maturity is in some way linked to feeding in some earlier periods. For salmon it has thus been found that the timing of growth within a year is important and fast growth in late winter or early spring leads to maturation but fast growth in 
late spring or summer does not (Rowe and Thorpe, 1990). The conclusion from these studies appears to be that if the growing season starts too late, then there will be insufficient time to acquire reserves for spawning (Rowe and Thorpe, 1990).

There are of course other factors such as increased daylight, water temperature and food supply or decreased density which may increase the proportion mature and affect growth. For example, Millar (1992) and Millar and Myers (MS 1990), investigating cod off Newfoundland, found that temperature and density were important factors in describing growth, but links to food supply have not been found in this area. Similarly, Jakobsson et al. (1993) report on density-related factors in the growth and maturation of summer-spawning herring (Clupea harengus) in Icelandic waters. In this context, however, it must be noted that Rijnsdorp et al. (1991) found no evidence of density dependent growth, of juveniles or adults, in the North Sea for plaice, sole (Solea solea) or cod and therefore density dependent growth does not appear to be a common phenomenon.

Bohlin et al. (1994), analysing sea trout (Salmo trutta) found that maturing male parr were bigger in the previous year than non-maturing fish. After maturation, immature fish grew faster than mature. After maturation, salmon and sea trout somatic growth slows but for plaice there is a time delay (Rijnsdorp, 1993). This may be related to differences in time scale of maturation between the species. Plaice being affected by growth history and salmon by more recent growth.

\section{Conceptual models}

The basic purpose of the present paper is to throw some light on the relationship between growth and maturation. A fundamental problem in this is that the mature fish which spawn at a given age may have matured for the first time either in the same or an earlier season.

Various models can be envisaged for the interrelationship between the maturation process and growth. This topic has been given consideration in the fisheries literature as well as in the general ecological literature, where models for reproductive tactics have been given considerable attention (e.g. Wootton (1992)).
The timing of the onset of maturity may be thought of and modelled in widely different ways. One such approach is taken in Beverton et al. (1993) and Vilhjálmsson (1994) where "maturation cohorts" are studied. A maturation cohort is defined as the group of fish of a certain year-class which mature at the same age. This approach is inherently reasonable if maturation is for example defined through a genetic trait so that maturation at a certain age defines a group of individuals which have certain population characteristics different from those maturing at a different age. In this setting the maturation process can be thought of as a driving force which will affect for example maturity-dependent growth etc. Some studies have in fact shown that the age of maturation is at least partially under genetic control for some teleosts such as chinook salmon (Oncorhynchus tsawytscha) (Hankin et al., 1993).

On the other hand, it has been found for haddock that maturation-related factors may vary in response to non-genetic effects such as increased food supply (Hislop et al., 1978; Sonina, 1981; Kovtsova, MS 1987, MS 1993), population abundance (Sonina, 1981; Kovtsova, MS 1987, MS 1993; Waiwood, 1989) and temperature (Sonina, 1981; Kovtsova, MS 1987, MS 1993; Hodder 1963, 1965).

According to these theories, early maturation would be a consequence of increased growth of immature fish. If this is the case, then maturation is more appropriately modelled as a consequence of other factors rather than as a driving force. If reduced growth is a consequence of the maturation process, it is possible that, in the von Bertalanffy model, early maturation simply shows up as a higher $\mathrm{K}$-value and lower L-infinity.

Related work on other species of fish indicates that the feeding level at an early stage is an important factor in deciding whether fish mature early. For example, it has been found that salmon maturation may be delayed through reduced feeding (Rowe and Thorpe, 1990; Thorpe et al., 1990) or starvation (Reimers et al., 1993).

Although fecundity will not be considered per $s e$ in this paper, it is of interest to note that reduced feeding levels have been found to lower fecundity and egg size (Springate et al., 1985; Vladyakov, 
1956; Wootton, 1973; Townshend and Wootton, 1984). Rijnsdorp et al. (1991) illustrate for plaice, that when somatic growth of plaice increases by $25 \%$, the percentage of mature fish increases by $10 \%$, for sole the absolute ovary weight increases as the condition factor increases but maturation does not seem linked to growth. For cod, however, the results of Rijnsdorp et al. (1991) were conflicting in that the somatic growth seemed to vary randomly with no relation to maturity, but the fecundity seemed to increase as the spawning stock decreased.

All of these results point in the same general direction: well-fed fish seem to mature earlier, producing more eggs and larger eggs. An appropriate model should therefore be able to predict that fish which initially grow fast mature early.

The other side of the coin concerns the effect that maturation has on subsequent growth. Many studies are available on this topic and the basic conclusion seems to be that fish will try to maintain a minimum egg weight to body weight ratio (Wootton and Evans, 1975; Kjesbu et al., 1991). Good growth prior to spawning will correspond to sufficient energy accumulation that the fish will not lose somatic weight, whereas if the fish does not acquire enough food prior to spawning, it will lose weight when developing gonads.

The net effect of early maturation is not obvious, as for example Atlantic salmon, have in some instances been found to be able to regain the weight lost due to early maturation and in fact reach the same weight as their immature siblings.

The above considerations indicate that a highly plausible model for the growth and maturation process would be one where increased growth at an early stage affects maturation which again affects later growth. There are also strong indications of a need to consider not only maturation and weight but also to consider fecundity along with egg size when looking at the relationship between spawning stock biomass and the number of surviving offspring.

To study the growth/maturation relationships one would ideally use experiments where individual fish are tracked and measured throughout their lifetime (Hawkins et al., 1967). A related approach is to use maturation cohorts along with back-calculated individual length-(or weight-) at-age. Otoliths have been extensively used as indicators of histori- cal growth of individual fish. Although the approach has often proved useful, several authors have found problems with techniques of back-calculation. For example, poor environmental conditions may lead to slow somatic growth but continued otolith growth resulting in the observation that slow growing fish have relatively larger otoliths. These confounding issues are commonly described as bias (Campana, 1990) or as a change in the relation between scale/ otolith and body growth (Thompson, 1929).

On the other hand, the primary problem with using the basic concept of maturation cohorts is, of course, that the timing of onset of maturity is not readily known with annual spawners such as haddock. In order to define a maturation cohort, some indicator in the otolith is required, and although such indicators have been found in Arcto-Norwegian cod (Beverton et al., 1993), such indicators have yet to be quantified for haddock in Icelandic waters. If such a signal exists in the otolith, it should be possible to extract from the otolith growth curves.

A point worth noting is that it may be easier to find a cause for fish staying immature rather than searching for the cause of maturation. In particular, the immature fish at a certain age have been immature for their entire lifespan, whereas it is not known when the mature fish changed their status.

\section{Materials}

In the present analysis, individual sliced haddock otoliths were scanned (Fig. 1) and radii measured in three directions from the centre or the edge of the first annual ring, to the outer annuli. A total of 236 sliced otoliths were available for this analysis, where the emphasis was on samples collected during 1992 and 1994 containing the abundant 1989 and 1990 year-classes. Most of the samples were collected during the spawning season and all from the spawning ground off the south-west coast of Iceland so a high proportion of the fish would be expected to be mature and the maturity stage easy to determine. Further biological data available on each individual haddock include length, sex, maturity and age.

Data on haddock from the March groundfish survey in Icelandic waters (Pálsson et al., 1989) are used to obtain various indicators of mean length and maturity for different areas and age groups. The survey covers the marine area around Iceland, down 


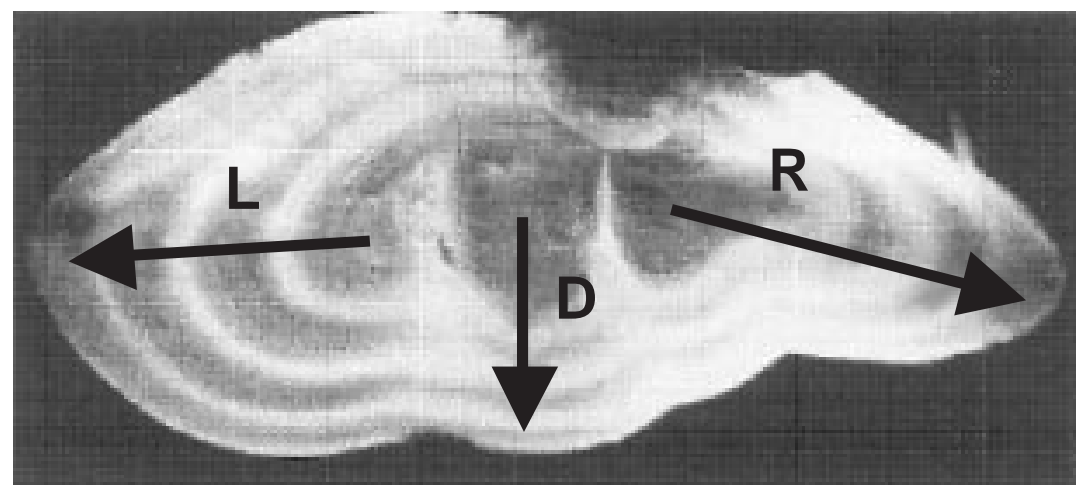

Fig. 1. Haddock otolith with measured directions indicated, left (L) down (D) and right (R).

to $500 \mathrm{~m}$, which includes the entire distribution area of haddock.

\section{Analysis}

In order to indicate whether (and how) otolith growth relates to somatic growth, the measured otolith radii need to be compared to actual fish length. This is done through plots and simple models. The first step in this process is to determine whether and how the otolith radii are linked to length.

Although conversion factors and back-calculations can be used to estimate true historical length at previous ages, this is not necessary. Rather, as the annual otolith increments are linked to growth (possibly in a non-linear fashion), and the whole point is to explain the growth-maturation link, the otolith radii are used as a proxy for growth and used directly for comparing growth and maturation. This direct use of the otolith dimensions avoids problems involved in back-calculations.

If there is a growth-maturation link, then certain patterns of individual growth curves should correspond to certain maturation patterns and, conversely, it may be expected that fish which matured in a certain year should be distinguishable through their growth curves. As a first step, therefore, the growth curves of otolith radii are grouped together into groups of similar historical growth using cluster analysis.

The aim of cluster analysis is to create groups, which are internally cohesive and externally isolated. Cluster analysis was applied to the otolith radii using hierarchical agglomeration where each iteration merges two groups to form a new group with the merger chosen to minimise the sum of the within group sum of squares (E.S.S.):

$$
\text { E.S.S. }=1 / c g a \sum_{k=1}^{c} \sum_{j=1}^{g} \sum_{i=1}^{a}\left(x_{i j k}-\bar{x}_{i . k}\right)^{2},
$$

where $a$ is the maximum age considered, $x_{i j k}$ the otolith radius at age $i$, there are $g$ otoliths in a group and $c$ groups within the dendrogram.

At the end of the process all individuals are joined in a single group and the pattern of agglomeration can be displayed in a dendrogram where the height of the mergers represents the E.E.S.

It is possible to extend the methodology to include all available data. In particular, as the cluster analysis is based on Euclidean distance (mean across ages), growth curves incorporating a different number of age groups can be compared.

Data from the groundfish survey in Icelandic waters are analysed simply by using sampled otolith, age, length and maturity data in order to obtain such information as length-at-age, maturity-atage, etc.

The emphasis is on female haddock for most of the analysis, although some comparisons will also be made for males. Although the females may be more important in terms of the spawning potential, changes in growth of males will affect the total yields of haddock and thus may affect future predictions of yield potential from the stock. As seen in Tables 3-6, temporal variation in maturity-at-age is much greater for males than females. 
TABLE 3. Percentage mature at age based on male haddock caught in March groundfish survey.

\begin{tabular}{lrrrrrrrrrr}
\hline \hline Age & 1988 & 1989 & 1990 & 1991 & 1992 & 1993 & 1994 & 1995 & 1996 & 1997 \\
\hline 1 & 0 & 0 & 0 & 0 & 0 & 0 & 13 & 0 & 0 & 0 \\
2 & 3 & 4 & 10 & 5 & 5 & 12 & 32 & 17 & 0 & 11 \\
3 & 30 & 21 & 32 & 17 & 21 & 30 & 27 & 33 & 10 & 32 \\
4 & 59 & 56 & 67 & 51 & 44 & 53 & 60 & 34 & 15 & 45 \\
5 & 85 & 78 & 84 & 68 & 84 & 65 & 78 & 75 & 37 & 55 \\
6 & 85 & 87 & 88 & 83 & 91 & 89 & 93 & 86 & 55 & 73 \\
7 & 92 & 100 & 100 & 92 & 96 & 100 & 100 & 100 & 70 & 80 \\
8 & 98 & 100 & 67 & 0 & 80 & 92 & 80 & 100 & 82 & 93 \\
\hline
\end{tabular}

TABLE 4. Percentage mature at age based on male haddock caught in March groundfish survey (spawning ground).

\begin{tabular}{rrrrrrrrrrr}
\hline \hline Age & 1988 & 1989 & 1990 & 1991 & 1992 & 1993 & 1994 & 1995 & 1996 & 1997 \\
\hline 1 & 0 & 0 & 0 & 0 & 0 & 0 & 0 & 0 & 0 & 20 \\
2 & 2 & 13 & 52 & 17 & 18 & 46 & 48 & 32 & 0 & 43 \\
3 & 47 & 46 & 68 & 45 & 49 & 64 & 58 & 39 & 15 & 61 \\
4 & 81 & 69 & 82 & 89 & 67 & 68 & 81 & 52 & 32 & 59 \\
5 & 94 & 90 & 88 & 83 & 95 & 84 & 88 & 81 & 52 & 75 \\
6 & 100 & 90 & 90 & 90 & 97 & 100 & 90 & 78 & 76 & 83 \\
7 & 100 & 100 & 100 & 96 & 100 & 100 & 100 & 100 & 87 & 90 \\
8 & 100 & 100 & 67 & - & 100 & 90 & 75 & - & 92 & - \\
\hline
\end{tabular}

TABLE 5. Percentage mature at age based on female haddock caught in March groundfish survey.

\begin{tabular}{rrrrrrrrrrr}
\hline \hline Age & 1988 & 1989 & 1990 & 1991 & 1992 & 1993 & 1994 & 1995 & 1996 & 1997 \\
\hline 1 & 0 & 0 & 0 & 0 & 0 & 0 & 0 & 0 & 0 & 10 \\
2 & 0 & 0 & 2 & 0 & 0 & 0 & 0 & 0 & 0 & 0 \\
3 & 8 & 8 & 16 & 4 & 7 & 10 & 15 & 10 & 7 & 17 \\
4 & 23 & 31 & 33 & 24 & 12 & 14 & 28 & 10 & 17 & 28 \\
5 & 51 & 51 & 64 & 53 & 47 & 36 & 59 & 48 & 35 & 37 \\
6 & 72 & 73 & 75 & 67 & 83 & 71 & 71 & 62 & 64 & 60 \\
7 & 86 & 100 & 83 & 79 & 76 & 75 & 100 & 50 & 67 & 73 \\
8 & 81 & 100 & 100 & 50 & 83 & 81 & 100 & - & 67 & 88 \\
\hline
\end{tabular}

TABLE 6. Percentage mature at age based on female haddock caught in March groundfish survey (spawning ground).

\begin{tabular}{rrrrrrrrrrr}
\hline \hline Age & 1988 & 1989 & 1990 & 1991 & 1992 & 1993 & 1994 & 1995 & 1996 & 1997 \\
\hline 1 & 0 & 0 & 0 & 0 & 0 & 0 & 0 & 0 & 0 & 0 \\
2 & 0 & 0 & 13 & 0 & 0 & 0 & 0 & 0 & 0 & 0 \\
3 & 15 & 16 & 39 & 15 & 18 & 28 & 31 & 15 & 15 & 24 \\
4 & 40 & 46 & 55 & 49 & 45 & 34 & 59 & 25 & 24 & 47 \\
5 & 70 & 71 & 70 & 63 & 71 & 64 & 74 & 69 & 50 & 50 \\
6 & 87 & 75 & 82 & 72 & 85 & 75 & 82 & 67 & 67 & 80 \\
7 & 98 & 100 & 93 & 95 & 83 & 100 & 100 & 0 & 55 & 79 \\
8 & 93 & 100 & 100 & 50 & 88 & 80 & 100 & - & 100 & 100 \\
\hline
\end{tabular}




\section{Results}

\section{Relating otolith growth and somatic growth}

The most suitable direction of measurement of otolith radii was taken to be the longest (to the right (R) in Fig. 1), as it correlated the closest with length at catch (Table 7). The shorter side of the lateral axis however, correlated better with the length at catch of the 3-and 4-year-old immature fish. If this is due to the problem of otolith deposition continuing after the cessation of somatic growth, then it may be the more appropriate direction.

Although the distance from age 1 to the border of the otolith is the best predictor of length, age is a significant addition to an ANOVA model describing length as a function of otolith size and fish age (Table 8). This implies that there is unexplained variation in the way otolith radii and fish length increase, not explained by a simple linear link between the two.

The fact that the distance from age 1 to the border is a better predictor of length than the distance from the centre is useful as there are problems in deciding where the "centre" of the otolith is.

\section{Spatial and density-related variation in growth}

Earlier results indicate that there may be small areas where haddock grow much less than in other areas (Jónsson and Gudfinnsson, MS 1998). This is also seen from the groundfish survey, where there are highly significant variations in length-at-age at different stations (Table 9). In order to avoid the effects of intra-haul correlations (Pennington and Vølstad, 1994), an analysis of variance was done based on the median length at age 3 for those stations where age 3 haddock had occurred every one of the years 1992-97. A two-way with a year and station effect yielded significant results in both variables (Table 10) with the spatial effect highly significant.

The growth curves of different year-classes, based on the entire survey area, are shown in Fig. 2. For the total area it is seen that the abundant 1989 year-class is followed by the slower growing 1990 and 1991 year-classes. For the spawning area a very different pattern emerges, as seen in Fig. 3 and the indications are not nearly as clear as for the total area.

\section{Formal statistical tests of growth and maturity relationships}

The otolith data can be used to investigate the differences in historical growth of different groups of fish. A simple t-test on the growth in the penultimate year yields a significant difference between the haddock which were mature and those which were immature at age $4(p=0.012$, based on those caught and sex staged at age 4 ). Those caught at age 3 did not show a significant difference in the penultimate growth $(p=0.30)$.

TABLE 7. Correlations between length at catch and otolith radii in three different directions (left, right and down) and from the centre or border of age 1 radius.

\begin{tabular}{|c|c|c|c|c|c|c|}
\hline & \multicolumn{2}{|c|}{$\mathrm{L}$} & \multicolumn{2}{|c|}{$\mathrm{R}$} & \multicolumn{2}{|c|}{$\mathrm{D}$} \\
\hline & Centre & Age 1 & Centre & Age 1 & Centre & Age 1 \\
\hline Length (all) & 0.845 & 0.848 & 0.866 & 0.902 & 0.838 & 0.861 \\
\hline Length (immature) & 0.865 & 0.856 & 0.750 & 0.861 & 0.833 & 0.821 \\
\hline Length (mature) & 0.727 & 0.736 & 0.791 & 0.846 & 0.762 & 0.783 \\
\hline
\end{tabular}

TABLE 8. ANOVA results from describing ln (length) of haddock as a function of ln (otolith radius) and age.

\begin{tabular}{lccccc}
\hline \hline Term & Sum of & Sur & & \\
\hline ln (radii) & 1 & 5.514 & 5.514 & 732.626 & 0 \\
Age & 1 & 0.126 & 0.126 & 16.745 & 0.00008 \\
Residuals & 111 & 0.835 & 0.007 & & \\
\hline
\end{tabular}


TABLE 9. Median length of haddock at age 3 by station and year, for groundfish survey stations with otolith samples in all years from 1992-97.

\begin{tabular}{lllllll}
\hline \hline Station & 1992 & 1993 & 1994 & 1995 & 1996 & 1997 \\
\hline 31701 & 41.5 & 37.0 & 34.0 & 36.0 & 38.0 & 32.0 \\
31712 & 40.5 & 37.0 & 37.0 & 37.0 & 38.0 & 33.0 \\
31912 & 32.0 & 31.0 & 31.0 & 30.0 & 36.0 & 34.5 \\
32011 & 32.0 & 31.0 & 32.0 & 34.0 & 33.5 & 37.0 \\
32012 & 34.0 & 30.0 & 31.0 & 33.0 & 32.0 & 34.0 \\
32111 & 33.5 & 33.0 & 35.0 & 34.0 & 30.0 & 31.5 \\
36411 & 45.5 & 37.0 & 34.0 & 39.0 & 40.0 & 37.0 \\
36501 & 40.0 & 37.0 & 33.5 & 35.0 & 36.0 & 38.0 \\
36511 & 40.0 & 40.0 & 31.0 & 34.0 & 34.0 & 33.0 \\
37201 & 36.5 & 33.0 & 37.0 & 35.5 & 37.0 & 36.0 \\
37311 & 33.0 & 36.0 & 35.5 & 36.0 & 42.0 & 35.0 \\
37312 & 33.0 & 38.0 & 35.0 & 41.0 & 41.0 & 37.5 \\
\hline
\end{tabular}

TABLE 10. ANOVA results from describing median length of haddock at age 3 as a station and year effect.

\begin{tabular}{lccccc}
\hline \hline Term & Df & $\begin{array}{c}\text { Sum of } \\
\text { Sq. }\end{array}$ & Mean Sq. & F Value & $\operatorname{Pr}(\mathrm{F})$ \\
\hline Factor (c(y)) & 5 & 71.4 & 14.27 & 2.101 & 0.07904 \\
Factor (c(r)) & 11 & 310.1 & 28.19 & 4.150 & 0.00018 \\
Residuals & 55 & 373.6 & 6.79 & & \\
\hline
\end{tabular}

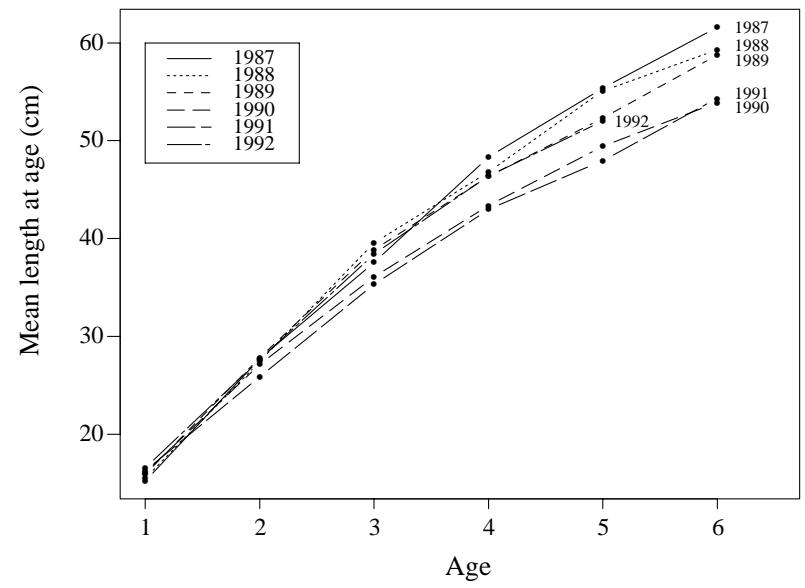

Fig. 2. Mean length of female haddock by year-class from groundfish survey. Entire area used in the analysis.

An analysis of variance indicates that when all data are used, the year-classes have significantly different (otolith) growth from age 3 to age 4 ( $p=$ $0.001)$. This result necessarily complicates the in-

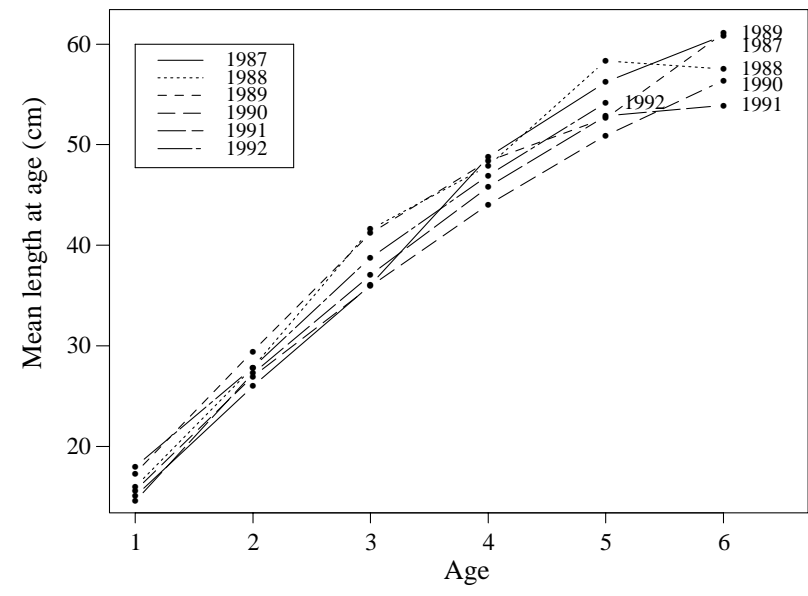

Fig. 3. Mean length of female haddock by year-class from groundfish survey. Spawning area used in the analysis.

terpretation, since maturity stage, age and yearclass are somewhat confounded. When only age 4 is considered, however, the data consist entirely of the 1990 year-class and the growth from age 3 to 
age 4 is significantly different for the different maturity stages with mature females growing faster.

The differences in (otolith) growth by area can be tested with an ANOVA of age 3 to age 4 growth on area (statistical rectangle). This gives a marginally significant difference $(p=0.09)$.

Similarly, there is a difference in otolith radius between mature and immature haddock with immature shorter for both age 3 and 4 , significantly so for age 4 ( $p=0.20$ and $p=0.02$ for ages 3 and 4 , respectively).

\section{Isolating growth groups}

The cluster analysis is applied to individual data on otolith radii from age 1 to the border of the otolith and used to group the individual haddock into 5 groups. A dendrogram describing such an analysis of otolith growth zones up to age three (based on fish age three or older) is given as Fig. 4 and up to age four in Fig. 5.

This analysis groups individual fish into groups which describe similar (otolith) growth histories. If there is a relationship between growth history and

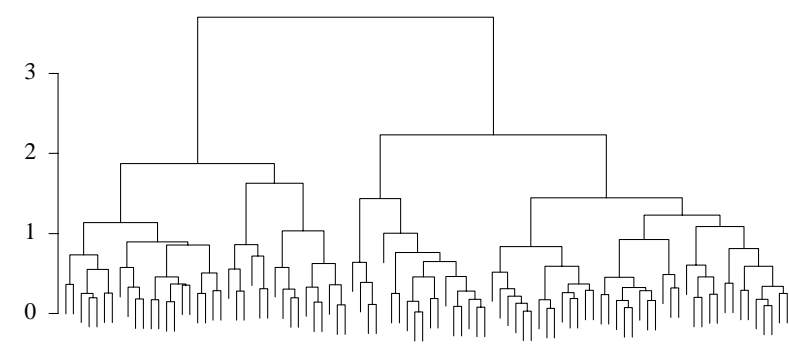

Fig. 4. Dendrogam illustrating relationship between otolith growth curves of female haddock up to age 3 .

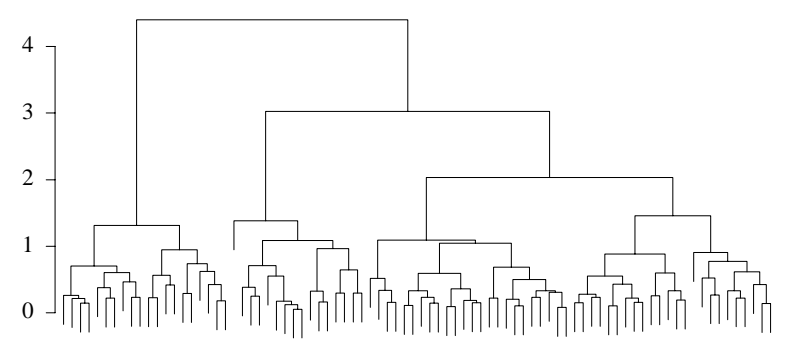

Fig. 5. Dendrogam illustrating relationship between otolith growth curves of female haddock up to age 4 . maturation, then the growth groups should show different maturity patterns.

\section{Comparing maturation of growth groups}

The mean otolith radius-at-age from the cluster analysis groups is plotted in Fig. 6 and 7. In these growth curves, it is seen that some clusters with similar final mean radii have different histories. In particular there is a separation of fish from different year-classes in these clusters as is shown in Table 11 which gives the proportional composition of year-classes in each cluster. The cluster of predominantly 1990 cohort grew faster younger, but

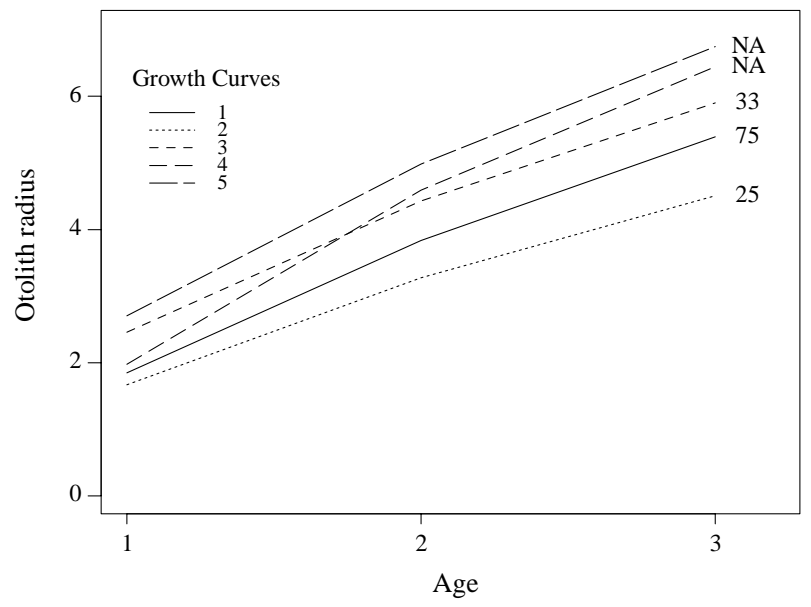

Fig. 6. Mean length in clusters based on grouping haddock growth curves up to age 3 . Numbers denote proportion mature.

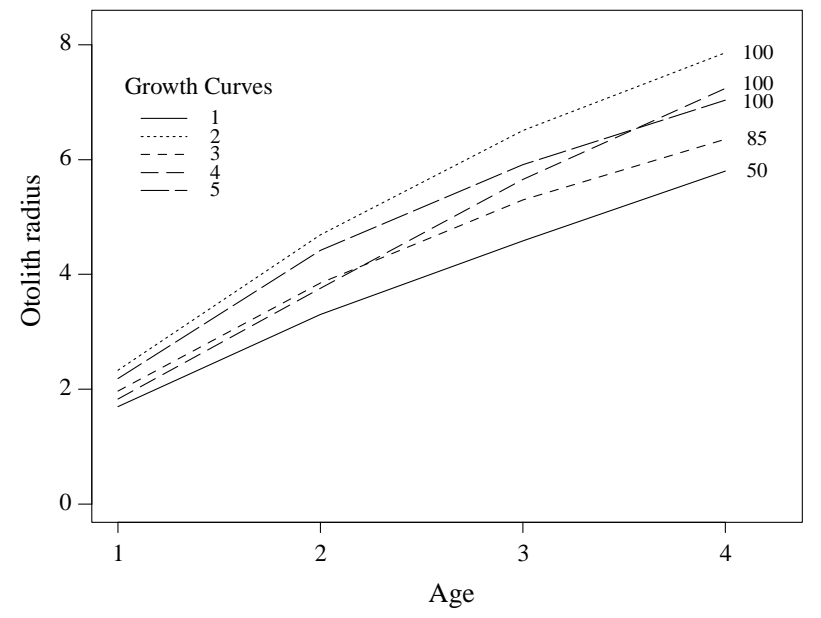

Fig. 7. Mean length in clusters based on grouping haddock growth curves up to age 4 . Numbers denote proportion mature. 
TABLE 11. Year-class composition of clusters derived from dendrograms of otolith growth curves up to age 4 .

\begin{tabular}{lccccc}
\hline \hline & \multicolumn{5}{c}{ Year-class } \\
\cline { 2 - 6 } Group & 1986 & 1987 & 1988 & 1989 & 1990 \\
\hline 1 & - & - & 6 & 56 & 38 \\
2 & 5 & - & - & 45 & 50 \\
3 & - & 4 & - & 33 & 62 \\
4 & - & 10 & 10 & 50 & 30 \\
5 & - & - & - & 29 & 71 \\
\hline
\end{tabular}

had significantly lower growth than the 1989 cohort between ages 3 and 4 . The reason for this appears to be that the year 1992 was a year of rapid growth with the 1989 cohort having fast growth from age 3 to 4 and the 1990 cohort rapid growth at age $2-3$. This is a confirmation of the difference in growth of these different year-classes seen above in the groundfish survey data (Fig. 2).

In this context it should be noted that the year 1992 corresponds to the change in age of maturity of Icelandic haddock, as observed in the catch data (Table 1).

The proportion mature of the final age used in the analyses is also given in these figures. It is seen that the immature fish are concentrated in the lower curves and the top curves are based on only mature fish. It can be seen in the plot of growth to age 3, that there were no fish caught at age 3 in the 2 highest growth curves, this corresponds to the relatively low growth of the 1989 cohort between age 2 and 3.

It is thus seen that the cluster analysis of growth appears to distinguish between different maturation regimes in that immature female haddock tend to have had slower growth than the mature females.

In addition to the above analysis where only complete data up to a given age is used, it is possible to extend the methodology to include all available data. In particular, since the cluster analysis is based on Euclidean distance (mean across ages) these can be computed between growth curves, which have a different number of age groups. Having grouped such growth curves, the proportion mature can be computed for every year on every growth curve, by considering those fish which were caught at that age on that growth curve. These analyses are presented in Fig. 8-9.

The same effect can be seen from Fig. 9 as from the growth and maturity figures to ages 3 and 4 . Here, there is a tendency for the immature fish to concentrate on the lower growth curves and the highest proportions mature are found on the top curve. It should be noted that the sample size in each cell is fairly small (Table 12).

\section{Discussion and Conclusions}

Otoliths provide valuable information on the growth history of individual fish. The otolith radius is, however, not simply a function of the length of the fish, since the age of the fish is a significant additional regression variable. The relationship appears to be non-linear and other explanatory

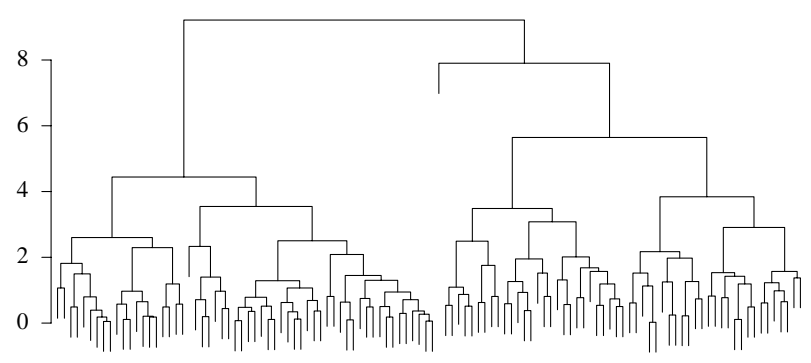

Fig. 8. Dendrogam illustrating relationship between growth curves of otolith radii using data from all available female haddock.

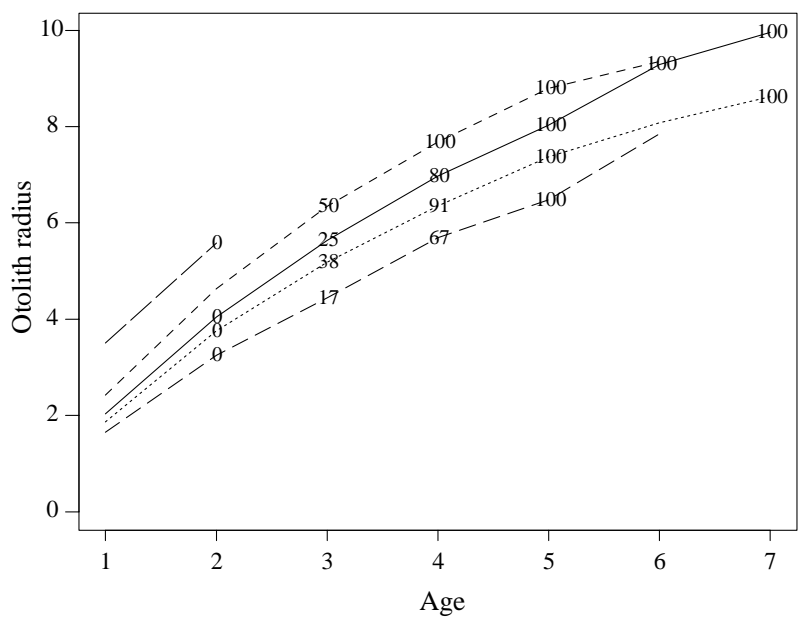

Fig. 9. Mean length in clusters based on grouping haddock based on all available data. Numbers on each curve denote proportion mature. 
TABLE 12. Percentage mature-at-age (size of sample) in each cluster derived from dendrogram of otolith growth curves using data from all available haddock.

\begin{tabular}{lccrrrr}
\hline \hline Group & 2 & 3 & 4 & 5 & 6 & 7 \\
\hline 1 & $0(2)$ & $25(4)$ & $80(10)$ & $100(5)$ & $100(1)$ & $100(1)$ \\
2 & $0(5)$ & $38(8)$ & $91(11)$ & $100(4)$ & - & $100(1)$ \\
3 & - & $50(2)$ & $100(10)$ & $100(8)$ & $100(1)$ & - \\
4 & $0(2)$ & $17(6)$ & $67(3)$ & $100(4)$ & - & - \\
5 & $0(1)$ & - & - & - & - & - \\
\hline
\end{tabular}

variables may need to be included. It is an important area of future research to establish the relationship between otolith (or scale) growth and somatic growth, in order to predict better the various effects in terms of yield and biomass.

Competition may slow the growth of yearclasses that follow a large year-class, in accordance with results obtained in the North Sea (Jones, 1983; Cushing, 1984; Cook and Armstrong, 1986; Hislop, 1996). When the entire area around Iceland is considered, it would appear that an abundant year-class affects the growth of the two subsequent yearclasses. The first abundant year-class does not seem affected by its own abundance. Density dependence, may however, take the form of reduced growth due to the total size of the population older than the cohort rather than the numbers in the cohort, reinforcing earlier conclusions. This sort of effect will have some effect on predictions of medium and long-term yield from the stock and needs to be taken into account. That the spawning ground does not show such a difference between the cohorts may be due to migration. Varying migration patterns may lead to very different and possibly constant or randomly varying mean length-at-age on the spawning grounds, even when the actual growth of individuals in the total population varies considerably.

As with other haddock populations (such as the North Sea and Barents Sea) age at maturation - and subsequently length at maturation is variable. Cluster analysis of otolith growth curves indicates that maturation is linked to the growth history and that otolith growth can be used to explain some of the variation in the maturation process. In particular, there are indications that immature individuals tend to have grown according to lower growth curves than the mature individuals (Table 12, Fig. 9). Clus- ter analysis (Table 11) also confirms the difference in growth of the different year-classes seen in the groundfish survey data (Fig. 2).

A considerable portion of the changes in observed proportion mature in the population is due to variable maturation of males. This indicates a need to compute "female" biomass rather than "spawning" biomass in assessments. Since there is little if any indication of reduced growth of females after maturation, such factors, if they exist, would primarily be expected for males. Further research should be conducted into the growth-maturation link for male haddock, as such factors may be important when predicting medium- or long-term yields from the stock.

It is important to consider spatial variation and selection of different areas for analysis may well lead to different results concerning which factors are important when considering growth.

This paper has largely ignored the precise form of the relationship between otolith radii and growth, since for the purpose of the present analysis it is sufficient to consider solely the otolith radii. It is, however, of considerable interest to establish the appropriate relationship in order to convert the otolith size as precisely as possible to historical fish length. There is a case to be made to consider also the relationship between fish length and scale radii in order to determine which type of back calculation is likely to have higher predictive power in terms of length. In many ways the scale growth is expected to be more tightly linked to the body growth of the individual fish and may potentially be a better indicator of historical growth, although the otoliths of haddock tend to be easier to read than the scales and are therefore routinely collected. 
The present analysis clearly demonstrates variation in growth history. In order to estimate the proportion mature at every age on several growth curves, which is needed to understand the link between maturity and growth, a considerable body of data is required. The present results can be seen as a first formulation of hypotheses, which need to be verified on different data sets, from other time periods

In particular, it would be of considerable interest to determine whether maturation can be linked to changes in growth in the year before maturation rather than simply overall faster growth. For such comparisons more growth curves need to be studied, since the simple grouping into 5 growth curves used here tends to group into curves which do not often intersect. The limited number of otoliths also means that the maturity data are quite sparse when estimating the proportion mature for each age on each growth curve. More data are therefore required for more detail to be available in the growth curves before firm conclusions can be drawn, although the indications of the growth-maturity relationship are strong from these plots.

\section{References}

ANON. MS 1998. Nytjastofnar sjávar 1996/97. Aflahorfur fiskveidiárid 1997/98 (State of marine stocks in Icelandic waters 1996/97, prospects for the quota year 1997/98). Marine Research Institute Report 56.

BEVERTON, R. J. H., and S. J. HOLT. 1957. On the Dynamics of Exploited Fish Populations. Fish and Fisheries Series - 11. Chapman and Hall.

BEVERTON, R. J. H., A. HYLEN, and O. J. OSTVEDT. 1993. Dynamics of maturation in long-lived fish populations. ICES Symposium No. 59

BOHLIN, T., C. DELLEFORS, and U. FAREM. 1994. Probability of first sexual maturation of male parr in wild sea-run brown trout (Salmo trutta) depends on condition factor $1 \mathrm{yr}$ in advance. Can. J. Fish. Aquat. Sci., 51: 1920-1926.

BROMLEY, P. J. 1989. Evidence for density-dependent growth in North Sea gadoids. J. Fish Biol., 51 (Suppl. A): 1920-1926.

CAMPANA, S. E. 1990. How reliable are growth backcalculations based on otoliths? Can. J. Fish. Aquat. Sci., 47: 2219-2227.

COOK, R. M., and D. W. ARMSTRONG. 1986. Stockrelated effects in the recruitment of North Sea haddock and whiting. ICES J. Mar. Sci., 42: 272-280.

CUSHING, D. H. 1984. The gadoid outburst in the North Sea. ICES J. Mar. Sci., 41, 159-166.

HANKIN, D. G., J. W. NICHOLAS, and T. W. DOWNEY.
1993. Evidence for inheritance of age at maturity in chinook salmon (Oncorhynchus tsawytscha). Can. J. Fish. Aquat. Sci., 50(2): 347-358.

HAWKINS, D. K., K. J. CHAPMAN, and D. J. SYMONDS. 1967. Spawning of haddock in captivity. Nature, 215: 923-925.

HELSER, T. E., and J. K. T. BRODZIAK. 1998. Impacts of density-dependent growth and maturation on assessment advice to rebuild depleted U.S. silver hake (Merluccius bilinearis) stocks. Can. J. Fish. Aquat. Sci., 55(4): 882-892

HISLOP, J. R. G., A. P. ROBB, and J. A. GAULD. 1978. Observations on effects of feeding level on growth and reproduction in haddock. Melanogrammus aeglefinus (L.) in captivity. J. Fish. Biol., 13: 8598.

HISLOP, J. R. G. 1988. The influence of maternal length and age on the size and weight of the eggs and the relative fecundity of the haddock, Melanogrammus aeglefinus, in British waters. J. Fish. Biol., 32: 923930.

1996. Changes in North Sea gadoid stocks. ICES J. Mar. Sci., 53: 1146-1156.

HODDER, V. M. 1963. Fecundity of Grand Bank haddock. J. Fish. Res. Board Can., 20(6): 1465-1487.

1965. The possible effects of temperature on the fecundity of Grand Bank haddock. ICNAF Spec. Pub., 6: 515-522.

JAKOBSSON, J., Á. GUDMUNDSDÓTTIR, and G. STEFÁNSSON. 1993. Stock related changes in biological parameters of the Icelandic summer spawning herring. Fish. Oceanogr., 2(3/4): 260-277.

JONES, R. 1983. An investigation of North Sea haddock (Melanogrammus aeglefinus) length-at-age data, with particular reference to the effects on growth of the outstanding year-classes of 1962 and 1967. ICES J. Mar. Sci., 41: 50-62.

JÓNSSON, E., and H. GUDFINNSSON. MS 1998. Ysurannsóknir a grunnslód fyrir Sudurlandi 19891995 (Haddock investigations off the south coast, 1989-1995). Marine Research Institute Report 68. In Icelandic.

KJESBU, O. S., J. KLUNGS $\varnothing$ YR, H. KRYVI, P. R. WITTHAMES, and M. Greer WALKER. 1991. Fecundity, atresia and egg size of captive Atlantic cod (Gadus morhua) in relation to proximate body composition. Can. J. Fish. Aquat. Sci., 48: 2333-2343.

KOVTSOVA, M. V. MS 1987. Dynamics of the size-age structure and maturation of Arcto-Norwegian haddock in relation to year class strength fluctuations. ICES C.M. Doc., No. G:26.

MS 1993. Growth rate and maturation of ArctoNorwegian haddock in 1987-1990. ICES C.M. Doc., No. G:58.

MILLAR, R. B., and R. A. MYERS. MS 1990. Modelling environmentally induced change in growth for Atlantic Canada cod stocks. ICES C.M. Doc., No. G:24.

MILLAR, R. B. 1992. Modelling environmental effects 
on growth of cod: fitting to growth increment data versus fitting to size-at-age data. ICES J. Mar. Sci., 49: 289-295.

MYERS, R. A., J. A. HUTCHINGS, and R. J. GIBSON. 1986. Variation in male parr maturation within and among populations of Atlantic salmon, Salmo salar. Can. J. Fish. Aquat. Sci., 43: 1242-1248.

PÁlSSON, Ó. K., E. JÓNSSON, S. A. SCHOPKA, G. STEFÁNSSON, and B. Æ. STEINARSSON. 1989. Icelandic groundfish survey data used to improve precision in stock assessments. J. Northw. Atl. Fish. Sci., 9: 53-72.

PENNINGTON, M., and J. H. VØLSTAD. 1994. Assessing the effect of intra-haul correlation and variable density on estimates of population characteristics from marine surveys. Biometrics, 50: 725-732.

REIMERS, E., A. D. KJÖRREFJORD, and S. M. STAVÖSTRAND. 1993. Compensatory growth and reduced maturation in second sea winter farmed Atlantic salmon following starvation in February and March. J. Fish. Biol., 43: 805-810.

RIJNSDORP, A. D., N. DAAN, F. A. VAN BEEK, and H. J. L. HEESSEN. 1991. Reproductive variability in North Sea plaice, sole and cod. ICES J. Mar. Sci., 47: 352-375.

RIJNSDORP, A. D. 1993. Relationship between Juvenile Growth and the Onset of Sexual Maturity of Female North Sea Plaice, Pleuronectes platessa. Can. J. Fish. Aquat. Sci., 50: 1617-1631.

ROSS, M. R., and G. A. NELSON. 1992. Influences of stock abundance and bottom-water temperature on growth dynamics of haddock and yellowtail flounder on Georges Bank. Trans. Am. Fish. Soc., 86: 291313 .

ROWE, D. K., and J. E. THORPE. 1990. Suppression of maturation in male Atlantic salmon (Salmo salar L.) parr by reduction in feeding and growth during spring months. Aquaculture, 86: 291-313.

ROWE, D. K., J. E. THORPE, and A. M. SHANKS. 1991. Role of fat stores in the maturation of male Atlantic salmon (Salmo salar) parr. Can. J. Fish. Aquat. Sci., 48: 405-413.

SONINA, M. A. 1981. Growth rate and sexual matura- tion of the haddock Melanogrammus aeglefinus. $J$. Ichthyol., 21: 85-97.

SPRINGATE, J. R. C., N. R. BROMAGE, and P. R. T. CUMARANATUNGA. 1985. The effects of different ration on fecundity and egg quality in the rainbow trout (Salmo gairdneri). In: Nutrition and feeding in fish. Cowey, Mackie and Bell (eds). Academic Press, London.

STEFÁNSSON, G. MS 1992. Notes on the stock-dynamics and assessments of the Icelandic cod stock. ICES C.M. Doc., No. G:71.

THOMPSON, H. 1929. General features in the biology of the haddock (Gadus aeglefinnus L.) in Icelandic waters in the period 1903-1926. Rapp. Proc.-Verb., LVII: $1-73$.

THORPE, J. E., C. TALBOT, M. S. MILES, and D. S. KEAY. 1990. Control of maturation in cultured Atlantic salmon, Salmo salar, in pumped seawater tanks, by restricting food intake. Aquaculture, 86: 315-326.

TOWNSHEND, T. J., and R. J. WOOTTON. 1984. Effects of food supply on the reproduction of the convict cichlid, Cichlasoma nigrofasciatum. J. Fish Biol., 24: 91-104.

VILHJÁLMSSON, H. 1994. The Icelandic capelin stock. Rit Fiskideildar.

VLADYAKOV, V. D. 1956. Fecundity in the speckled trout (Salvinus fontinalis) in Quebec lakes. J. Fish. Res. Board. Can., 13: 799-841.

WAIWOOD, K. G., and M. I. BUZETA. 1989. Reproductive biology of southwest Scotian shelf haddock (Melanogrammus aeglefinus). Can. J. Fish. Aquat. Sci., 46(Suppl. 1): 153-170.

WOOTTON, R. J. 1973. The effect of size of food ration on egg production in the female three-spined stickleback, Gasterosteus aculeatus L. J. Fish Biol., 5: 89-96.

1992. Ecology of teleost fishes. Chapman and Hall. 404 p.

WOOTTON, R. J., and G. W. EVANS. 1975. Cost of egg production in the three-spined stickleback (Gasterosteus aculeatus (L)). J. Fish Biol., 8: 385-395. 